\title{
How Uganda Reversed Its HIV Epidemic
}

\author{
Gary Slutkin • Sam Okware - Warren Naamara • \\ Don Sutherland • Donna Flanagan • Michel Carael • \\ Erik Blas · Paul Delay · Daniel Tarantola
}

Published online: 21 July 2006

(C) Springer Science+Business Media, Inc. 2006

\begin{abstract}
Uganda is one of only two countries in the world that has successfully reversed the course of its HIV epidemic. There remains much controversy about how Uganda's HIV prevalence declined in the 1990s. This article describes the prevention programs and activities that were implemented in Uganda during critical years in its HIV epidemic, 1987 to 1994. Multiple resources were aggregated to fuel HV pre-
\end{abstract}

\section{G. Slutkin}

University of Illinois - Chicago,

USA

S. Okware

Uganda Ministry of Health,

Uganda

W. Naamara

UNAIDS,

Ghana

D. Sutherland

World Health Organization, Geneva, Switzerland

D. Flanagan

Spokane Washington

M. Carael

Free University of Brussels, Belgium

E. Blas

World Health Organization,

Geneva, Switzerland

P. Delay

UNAIDS, Geneva, Switzerland

D. Tarantola

University of New South Wales,

Australia vention campaigns at multiple levels to a far greater degree than in neighboring countries. We conclude that the reversed direction of the HIV epidemic in Uganda was the direct result of these interventions and that other countries in the developing world could similarly prevent or reverse the escalation of HIV epidemics with greater availability of HIV prevention resources, and well designed programs that take efforts to a critical breadth and depth of effort.

Keywords AIDS · Uganda · Prevention · Epidemic

\section{Introduction}

Since the beginning of the World Health Organization's collaboration with developing countries, Uganda was for many years the only country in Africa and only one of two countries (the other Thailand) in the developing world to have clearly reversed its HIV epidemic (Asiimwe-Okiror et al., 1997; Mason, Markovitz, \& Kitsiripornchai, 1995; UNAIDS, 1998; USAID, 2003; US House of Representatives, Hearing on the Global AIDS crisis and pandemic in Africa, 2000), although more recently, other reports indicate additional countries are showing possible reductions (Gregson, Garnett, Nyamukapa, \& Hallet, 2006; Kibian, 2006; USAID, 2003). Uganda's changes remain the first, most extensive, and of largest scale of decline (USAID, 2003) but are still subject to controversy as to how these changes occurred (Parkhurst, 2002; Stoneburner \& Low-Beer, 2004).

With regard to the changes in Uganda, much has been written describing which sexual behaviors changed in the Uganda population (Asiimwe-Okiror et al., 1997; Stoneburner \& Carballo, 1997; Stoneburner, Low-beer, Barnett, \& Whiteside, 2002; UNAIDS, 1998), but there has still been little written about the strategies, activities and 
program elements that took place that affected these changes. In other words, the changes in sexual behaviors in Uganda that occurred during that time period are known - and the effects on the HIV epidemic are known, yet the continuously missing part of the discussion has been "why did these behavior changes occur?." Similarly why did these changes occur in Uganda and seemingly not in the neighboring countries at the time, or to that degree still anywhere in the developing world?

This article attempts to fill this gap. We offer our description of these activities as persons who were involved in Uganda's AIDS program's inception and the first seven years (1987-1994) of the program when its effects occurred. Simplistic explanations such as leadership, migration, or awareness of the deaths of others, seem unlikely to be responsible on their own since country leadership principally defines the will for programs and the willingness to ensure activities occur, but does not explain what actual activities did occurred. Regarding migration, changes in HIV prevalence occurred in at least seven and possibly nine towns and villages simultaneously in Uganda (Stoneburner et al., 2002), making migration an unlikely explanation. Also, since similarly high rates of infection (15\%-30\%) were seen in the major cities of at least four neighboring countries (i.e. Rwanda, Burundi, Zambia and Malawi) during the same years (Stoneburner \& Carballo, 1997; USAID, 2003) and without the same declines, we must look at what was the Uganda program itself. As will be seen, the program itself differed, both in substance and in intensity, from all neighboring programs in Africa.

This article focuses on the years when the HIV/AIDS program in Uganda was first formed through the time when serologically measured changes in HIV prevalence occurred. Our analysis is based on the country documents, national program plans and reports of that period, and our experiences as part of that program. An attempt is also made to provide comparisons with other national AIDS programs in Africa that occurred in the same years and to describe the major differences between Uganda's program and other programs in the region at the time. First we describe our sources of information followed by our description of the Uganda AIDS prevention activities and their implementation.

\section{Information sources}

This paper focuses principally on program strategies, processes and activities of the Uganda National AIDS Control Program (NACP) for the years 1987-1994. Although noted here, we do not provide an in depth analysis of the trends in sexual behavior or HIV changes themselves which have been analyzed elsewhere and repeatedly. This article draws on sources from Ugandan Ministry of Health records and reports, World Health Organization (WHO) records and reports on the country program and programs of neighboring countries, Uganda country assignment reports, the Uganda National Program Review, and plans and country assessments by WHO and USAID written at the time. We also rely on data from specialized studies performed at the time and reports of those of us who were engaged directly in the program reviews, planning and implementation of the Uganda AIDS program during those years, some of whom were also involved in implementation or assistance to implementation of neighboring African countries at the same time.

\section{Brief history of the Uganda National AIDS Control Program (NACP) 1986-1995}

AIDS cases were first recognized in Uganda in 1983, with the first 900 cases reported by 1986, rising to 6,000 cases by 1988 (Uganda AIDS Control Programme, 1989). By 1986$1987,86 \%$ of sex workers and $33 \%$ of lorry drivers studied were HIV positive and $14 \%$ of blood donors and $15 \%$ of antenatal clinic attendees in major urban centers were also HIV positive. In 1986, in response to these findings, the national government of Uganda formed the National Committee for the Prevention of AIDS (NCPA) and the NACP. The WHO assisted the government of Uganda in both of these endeavors beginning in January of 1987, when the first "emergency" national plan was written. Subsequently a short term plan (STP), and the 3-5 year medium term plan (MTP) were written in 1988-1989. A program review was performed in December of 1988 (the first of its kind in Africa and in the world), and the next MTP was drawn up immediately following the findings and recommendations of the first program review. All of these rapid and intense WHO assisted steps were set in motion for all countries in Africa, and subsequently for almost all countries in the world during this time. During the years 1987-1990, 120 countries developed NAPs, 40 developed MTPs, and 15 had program reviews before WHO all but disbanded in its prior formulation, and became less involved with direct country support (SIDA/AIDS WHO, 1992; Slutkin, 2000; Tarantola, 1996; US House of Representatives, 2000; WHO Global Programme on AIDS, 1987-1995).

During the years 1987-1990, although almost all AIDS control programs, especially those in East and Central Africa, were progressing, Uganda. was the first country in which the WHO worked with the concept of a single national plan and budget, which all donors would agree to use and fund to focus their respective aid, and with a local multi-donor round table aimed at meeting the targeted budget. Uganda was the first country to progress through all of the STP, MTP, joint donor meeting, program review and reprogramming processes. Uganda was then set up to lead the way among all countries in the extent of programming, the amount of on the ground national staffing, WHO staffing support, and global financial support (Mann, 1991; WHO, 1997). 
Emergency assistance - first plan in Africa

The strategies of Uganda's first national AIDS control plan of 1987 were described as "to mount an educational campaign to inform the public on the modes of transmission and ways to avoid infection," "to reduce transmission through blood transfusion by setting up laboratories to test all blood before transfusion and to reduce transfusion to a minimum," "to advocate careful sterilization of instruments and contaminated hospital areas to assure patient and health worker safety," and "to measure the extent of the outbreak and possible co-factors by case surveillance, seroprevalence studies and operational research projects" (Uganda, 1989). These were the usual strategies for all early AIDS programs (WHO Global Programme on AIDS, 1987-1995).

This initial plan was supported by a WHO grant of $\$ 400,000$ made available within weeks of the signature of the STP, and then \$1 million more was provided in emergency assistance. Blood was largely screened in the major urban areas, a health education program started, and the sentinel surveillance program initiated (Slutkin, Chin, Tarantola, \& Mann, 1988; Uganda, 1989). For the later two strategies, activities moved far in advance of other country programs at the time. This plan also laid the groundwork for the five-year plan, which was to be developed in 1989. The program review of 1988 summarized the accomplishments of the NACP of Uganda in its first 2 and half years.

\section{The first Uganda program review}

The program review of December 1988 (Ministry of Health Uganda, 1989) was performed for the stated purpose of reviewing accomplishments, adequacy, relevance, progress and effectiveness of stated activities, and to make recommendations for the next phase, in this case for the five year plan that was to be written in the following month. It should be noted that WHO Global Program on AIDS (GPA) at this time and the Ugandan government were both in an emergency mode of accelerated program development, cooperation and assistance.

The main findings of the Uganda NACP program review led to a series of recommendations. Program strengths highlighted by the review included: "continued and increased political commitment of the Government of Uganda and especially the President," "vital contribution(s) of non governmental organizations," and a "strong leadership role by ACP and an emerging coordinating role by (the national) AIDS Control Program (NACP) widely accepted by Government, non government agencies, and donors." Over 33 critical recommendations were made, commenting on the first two years of activities that were to instruct the next five years of work. Of these 33 recommendations, the following were thought important enough to be highlighted in the executive summary: "the intensity of the AIDS control activities must be accelerated especially at the district and community level"; "(the national level) ACP should take on a stronger (coordinating) role...," "prevention should remain the primary objective...," that "(there is a)lack of adequate renumeration for national staff . . . and that Uganda and WHO explore all possible ways of overcoming this serious problem...," and "(the) NACP . . . office needs to have more expertise in planning, manpower development, research direction, coordination, and administration" (Uganda, 1989).

The first 10 recommendations of the Uganda Program Review (Uganda, 1989) provided insight into what was in process and what was thought to be needed by the combined international and national expert review team. These recommendations were then, within weeks, integrated into the 1989-1990 plan. The main recommendations, quoted from the report, were the need for "stepwise application of well-conceived and integrated KAP/IEC strategies," "make these methods . . . available to all groups," "more widespread dissemination of factual information," "increased emphasis for illiterate people," "materials designed for groups at high risk, and for families with AIDS," "information that can be used by resistance committees (village level political structure through which the Musevini government operationalized new policies) to raise local awareness," "effective channels for distributing written and pictorial information," "training," "communication skills," teaching "training skills at district level," "training packages," "distributing training packages," "financial support . . . to enable district, community, and other training groups to run training courses," and "health educators to (be) fully equipped and functional within weeks rather than... several months (to perform this education in the districts)."

Regarding condoms, the NACP was advised by the cosponsored review only to "review the use of condoms as part of the strategy particularly where transmission rates are high." The Ministry of Health, the lead ministry for the Uganda program at the time and for the next several years, was not eager to embrace condoms, for a number of reasons that included availability (dependence), acceptability, and disposal, and the fact that putting trust in one measure was not strategic. These reasons were constantly cited by the program and President Musevini. The review repeatedly noted the need for an urgent push toward the rapid expansion of the information, education, communication and training.

The Uganda medium term plan (MTP) 1989-94

The 1989-1994 Five Year plan, and 1989-1990 First Year Project Plan and Budget directed the immediate acceleration of the program as outlined in the program review (Ministry 
Table 1 Uganda national AIDS control program budget 1989

\begin{tabular}{lc}
\hline Activity & Total $(\times 1$ mill. USD $)$ \\
\hline Management & 1.6 \\
Health education & 7.2 \\
Surveillance and care & 4.3 \\
Lab support & 5.0 \\
Total & 18.1 \\
\hline
\end{tabular}

Source: Uganda Aids Control Program 1989-90; Ministry of Health, Government of Uganda; Entebbe, Uganda 89.

of Health Uganda, 1989; Amana, 1990; Moodie et al., 1991; Uganda, 1993).

This plan's priority strategies and budget allocations are shown in Table 1. The sources of funds for the year 1989 were as follows: WHO Trust Fund $\$ 10.6$ million, Bilateral funds (e.g. from USAID, ODA, etc) $\$ 7.1$ million, and national (Ugandan) $\$ 0.5$ million. Therefore, the Uganda program grew from annual expenditures of $\$ 1.0 \mathrm{mil}$ to $\$ 4.0 \mathrm{mil}$ to $\$ 18$ million in its first three years. Dozens of organizations were involved in the management, planning and implementation of the Five Year Plan including local and international non-governmental organizations (NGOs), and all segments of Ugandan society. The management concerns discussed in the program review were addressed in part by assuring that the Ugandan NACP "remain the central coordinating body," and its staffing was enhanced to 45 Ministry of Health staff, supplemented by 6 WHO staff. Each of these levels of staffing was substantially larger than any other program on the continent. We do not recall any other country having a program of more than 10 local staff or 4 WHO staff at the time.

As can be seen in Table 1, the Ugandan health education (IEC) budget was greatly prioritized among all strategies implemented. The IEC program is discussed in more detail below as it is thought essential. As was the case at the time for all programs in central and east Africa, it was essentially demanded of WHO by the country's government that enough funds be made available to ensure a safe blood supply, and have the laboratory supplies and facilities to perform this function. The Ugandan program also became the first country to both field test HIV sentinel surveillance at antenatal clinics and other settings (Nsambya, Uganda being the first sentinel surveillance site in Africa and is still operational), and then the first country to expand this system initially to six sites, and then country wide (Slutkin et al., 1988; Slutkin, Chin, Tarantola, \& Mann, 1990).

However with this infrastructure in place, including management, lab support, blood screening, and HIV monitoring, it was then completely unique on the continent to have funds remaining for a national AIDS health education budget to be supported at the level noted. Full country AIDS program budgets for the six neighboring countries were all in the range
Table 2 Uganda AIDS health education budget 1989 and 1990 ( $\times$ 1,000 USD)

\begin{tabular}{lrr}
\hline Category & 1989 & 1990 \\
\hline Salaries & 164 & 203 \\
Consultants & 241 & 164 \\
Duty travel & 12 & 14 \\
Supplies-field projects & 238 & 209 \\
Equipment-field projects & 388 & 120 \\
Local costs & 1,724 & 1,539 \\
Program support costs & 360 & 292 \\
TOTALS & 3,128 & 2,541 \\
\hline
\end{tabular}

Source: Uganda Aids Control Program 1989-90; Ministry of Health, Government of Uganda; Entebbe, Uganda 89.

of \$1-4 million total (cf. \$18 million for Uganda). As was to be seen, the Uganda program was then free to prioritize and implement throughout the country the most widespread, extensive and well thought out information, education, and communication program for AIDS prevention (and care) of any country in Africa. As can be also seen in Table 2 (shown for both 1989 and 1990), the Uganda Health Education budget itself was to specifically prioritize local and decentralized programming, local rather than international expenses, and to ensure local staff salaries and perdiems.

In 1989, the first year in which financial information is available, $\$ 3.1$ million of the $\$ 7.2$ million available for health education activities were made available from the WHO Trust Fund. The additional $\$ 4.1$ million were made available from bilateral sources, e.g. UNICEF, USAID, U.S. Red Cross, MSF and U.S. and other University projects. Of the \$3.1 million, \$1.7 million was made available for local costs. Similarly $\$ 1.5$ million of the $\$ 2.5$ million spent from the WHO Trust fund IEC budget was used for local costs. The 1991 Evaluation of the Uganda IEC activities stated that the DAMP and the ACP Mass Media activities were "two of the most visible of the NACP's projects and together utilize more than half of the IEC budget."

The 1989-1992 health education campaign

The Health Education (Information, education and communication; IEC) Campaign was to be the center of the Uganda program (Amana, 1990; Moodie et al., 1991; Uganda, 1989). The main goals of the Ugandan IEC program were three fold: 1) mobilization of all formal and informal sectors of Ugandan society; 2) providing IEC materials to all districts; and 3) district level, decentralized information and training. The principal activities were, as proposed by the program review and plan, the development of training packages and a "training of trainers" program for "all sectors," public education materials development and dissemination, and district level "mass mobilization" with "cross fertilization" from one 
Table 3 The 1982-92 AIDS information, education and communication (IEC) campaign sectors trained (partial listing)

\begin{tabular}{ll}
\hline Resistance committees & Agricultural workers \\
Police & Social mobilization \\
Traditional healers & Prisons \\
Schools & Universities \\
Youth & Media \\
Midwives & Army \\
Performance artists & Women's groups \\
Religious organizations & Family planning workers \\
Refugees & \\
\hline
\end{tabular}

Source: Uganda Aids Control Program 1989-90; Ministry of Health, Government of Uganda; Entebbe, Uganda 89.

district to another, training educators from one district to be used in the next district. This IEC campaign was led by the Ugandan Ministry of Health with technical and implementing assistance from WHO and had very active support and involvement from UNICEF and from several critically important NGOs. The specific program elements are described below.

\section{Training of trainers}

A partial listing of the specific "sectors" trained by the program are listed in Table 3. The "main focus" points of this multi-sector training were: correct information on how HIV/AIDs is and isn't transmitted; destigmatization; care and compassion; and condoms (Moodie et al., 1991; Uganda, 1989). Each of these sectors had specific training activities that began centrally with workshops for Ministries or other "central level" personnel, e.g. for permanent secretaries, ministries, parliamentarians, police, teachers, family planning association workers, resistance committee mem- bers, etc, and then proceeded with a "top - down" or "center - out" cascade of information dissemination and training. These training activities were meant mostly to simply convey the correct information about how HIV/AIDS is and is not transmitted, and that persons with AIDS were to be treated humanely.

\section{District mobilization}

The District AIDS Mobilization Project (DAMP) model implemented by the Ugandan IEC program is shown in Fig. 1 . Resources used for the DAMP included 18 paid health educators of the Ministry of Health, 6 local graphic designers, and 3 international consultants (including 1 from WHO, and 1 from UNICEF). Seven vehicles for the central pool, 34 vehicles for the district health educators, and 40 motorcycles were provided by the international community and by the government for this campaign. Two film vans for mass addresses and a number of hand held megaphones and other public address systems were also purchased or made available for this campaign.

The District course content as noted in a WHO funded special IEC review stressed 11 topics including scientific overview, basic prevention messages, common questions and misconceptions, communicating with high risk groups, cultural practices, special concerns of women, effective communication skills, care, and counseling. District level activities used to convey this content included public gatherings, plays, songs, contests, and the distribution and discussion of posters, leaflets, fliers, comic books, documentaries and videos. The basic content of these district, village and community sessions were of a type of allowing the correct information to be discussed, to give it time, to allow everyone to be
Fig. 1 District mobilization implementation model (DAMP). Source: Moodie, et al. $\mathrm{ACP} / \mathrm{MOH}$ Uganda and WHO/GPA, 1991

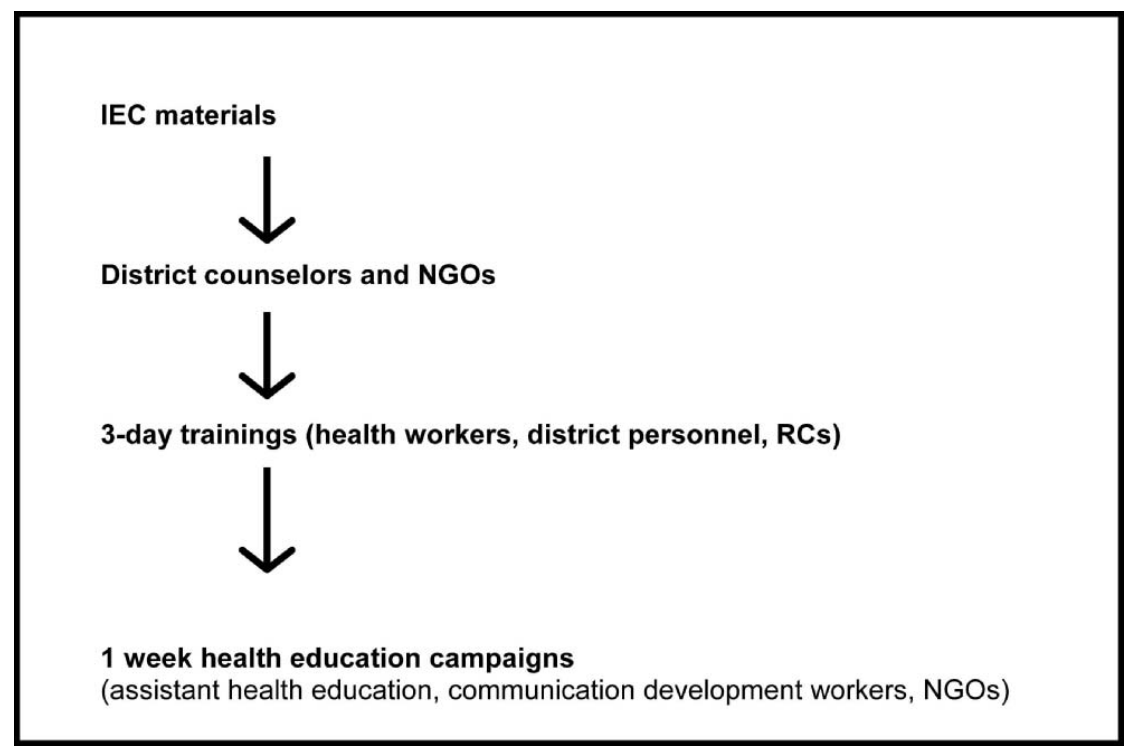


involved and to disseminate accurate information for the population in order for their to be an adequate opportunity to mull over, discuss between each other, understand, and facilitate a critical mass of persons who knew the facts. Norm change was intended to follow facilitated group decision-making.

IEC materials on AIDS such as posters, pamphlets, and booklets were developed and translated into local languages, and distributed to District Councilors, Resistance Councilors and to members of NGOs at training workshops. Three day seminars were held for health workers, followed by two day seminars for Resistance Councilors and district department heads, and sub-county chiefs. The general public was to get their materials through the Resistance Councilors system and other key people such as "mass mobilizers" and community development workers.

Resistance committees were political administrative units that graduated into each other from the Resistance Councilors that was made up of 9 households. Resistance committees were later to be called local councils or local area councils, but they maintained the same function. These training activities were followed by a one week health education campaign conducted by Resistance Councilors in collaboration with assistant health educators, other health educators, community development workers and NGOs. The DAMP activities and the training of trainers through multiple formal and informal natural and other infrastructures would serve to cross fertilize, in other words allow multiple messengers to come at individuals and groups through multiple channels, but with the same message.

Although DAMP was the "big concept," UNICEF funded health education activities included a community Health Education Network (HEN) with community based health educators imbedded in the community, meant to sustain DAMP, and SHAPE (School Health Education Project). Both of these activities cross fertilized with and were thought to have augmented the DAMP. Parents and the community were to get information from HEN and their children got information from the schools - so there would be multiple channels alongside the district level work, and specific synergy at the household level.

\section{Country wide messaging}

The dominant message of the Ugandan program, as is well known, and which was well known at the time both throughout Uganda and throughout Africa (as the Uganda message) was "Zero Grazing," alluding to the traditional way cattle were fenced in, or tied to a stick to limit grazing outside their own pasture. This clearly meant "stick to one partner" which was what was frequently said following the message or by way of explanation. This was a message of "fidelity" although that word was rarely used at the time, as it not only pertained to during marriage, but to during dating as well. One study in1990 supported by WHO/GPA reported higher village recall of the saying or having seen the posters "Love Faithfully" (30\%), and "Love Carefully" (25\%) than "Zero Grazing." Over 70\% of those aware of "Love faithfully" interpreted this to mean "stick to one partner"; over $50 \%$ of those who heard or saw "Love carefully" understood it to meant "choose your partner carefully" (which became a large confusion in Uganda), and over half of those who saw or heard "zero grazing" thought it to mean "stick to one partner."

All options including delaying sex, not engaging in sex, sticking to one partner, and to a lesser extent, using condoms were also described in the materials and discussions in trainings and in the district level courses and discussions. The posters at the time emphasized a cow in a pasture surrounded by a fence, and many "Thank God I said no" posters, as well as messages of care and compassion. The word abstinence per se was rarely if ever heard in Ministry conversations, although delaying onset of sex was part of usual information. Although all means of transmission noted here were provided as information, we believe the actual "ABC phrase" came out of the USAID in the mid or late $90 \mathrm{~s}$, and was not seen in any of the country plans or program documents, or known at the time of the first 6-7 years of the Uganda program.

\section{Materials development and dissemination}

There was an enormous emphasis in Uganda on material development, production and reproduction, and active dissemination out of the capital to the districts. Local graphic artists held subsidized workshops with local residents to design materials and information packets for use in the trainings and DAMP activities. A full time printing press was paid for by WHO and put into the Ministry of Health along with other equipment and staffing support to intentionally "enhance the capacity of the Ugandan Ministry of Health - Health Education Unit." A full time "U.N. Volunteer" (UNV), funded by WHO/GPA, was additionally supported for the Uganda program to run the printing press. The instructions to the UNV were to continue to print, produce, and disseminate materials no matter what else was occurring regarding the national program. Posters, leaflets, fliers, and comic books were produced by this and other means. Materials for persons with poor literacy skills were also developed and actively disseminated.

\section{Mass media}

Representatives from Ugandan radio and television were included in the program and planning process, and both radio (thought to reach over $87 \%$ of the population) and television were widely used. Short "jingles" were designed by 
NACP for radio to convey information on AIDS. The Ugandan daily paper MUNNO ran daily articles on AIDS. The weekly Topic and daily New Vision ran a combined 17 articles on AIDS in 1990. The New Vision ran the "AIDS Corner" on the last page of every issue that posed a question and provided an answer. This campaign ran daily for three consecutive years. The Q and A's were later compiled into booklets used in other countries. Ugandan TV (UTV) ran regular spots discussion programs and documentaries. Theater was used to convey messages and almost all theater groups developed plays incorporating HIV/AIDS messages. President Musevini, Dr. Okware - then National AIDS Program Director - and other Ministry officials were regular spokespersons in the media, and the program appeared to speak with one voice so there was little opportunity for confusion.

Church leaders and imams were a major sources of information for about $12 \%$ of the population, but between $81 \%$ and $95 \%$ of three villages reported having received messages on AIDS from the church. Fidelity and monogamy were emphasized "in addition to abstinence." Eighty-five percent of respondents in the 1991 NACP study felt that abstinence "was not a practical prevention strategy or behavioral option for any or all members in their community"; $44 \%$ similarly felt that monogamy was not practical or possible at that time.

\section{Changes in social norms}

At the time there were several anecdotal reports of villages changing norms of the acceptability of sexual contacts between teachers, police and the military in terms of their relations with young women. These decisions were arrived at by group decision making - and these changes in enforced norms toward total unacceptability were also supported by Presidential directive at the time. The results reported were that teachers or police who did engage in sexual relations with young women and girls were removed from their assignments, and likewise forced to leave the towns or villages. The full extent of these specific changes in norms and practices is unknown.

\section{Changes in sexual behavior}

Between 1989 and 1995 changes occurred for the spectrum of relevant sexual behaviors (Asiimwe-Okiror et al., 1997; Atkinson, 1989; Singh, Darroch, \& Bankole, 2003; Stoneburner \& Carballo, 1997; 2003; USAID, 1998, 2003; US House of Representatives, Hearing on the Global AIDS crisis and pandemic in Africa, 2000), including toward delay in age of first intercourse (fewer initiated at young ages), lesser frequency of multiple partners, fewer non-regular part- ners, a narrowing of the age gap between girls and their male partners (USAID, 1998) and toward more condom use. The proportion of male and female youth aged 15-19 years old who reported that they have never had sex increased from $31 \%$ and $26 \%$ in 1989 , to $56 \%$ and $46 \%$ in 1995 respectively (Assimwe-Okror, 1997). It is reported that there was no general pattern of increased abstinence among those who had ever had sex (Singh et al., 2003), however overall sexual activity decreased among 15-19 year old men and women, and for most ages.

Condom use was unusual prior to 1989 and increased from $<1 \%$ to over $15 \%$ among unmarried women and men who had sex in the prior 4 weeks from the 1989 to 1995 period - with larger increases for younger ages; up to $50 \%$ in "last intercourse" for sexually active 15-17 year olds (Singh et al., 2003). In the NACP study between $30 \%$ and $60 \%$ of persons in the three districts studied reported having made some changes in their sexual behavior; the overwhelmingly greatest change made was in the reduction in the number of partners (Moodie et al., 1991). Which changes occurred may or may not correspond directly to what was promoted by the program.

\section{Changes in HIV prevalence}

Uganda's sentinel surveillance system was the earliest and most elaborate system of HIV monitoring in Africa at the time, allowing for continuous monitoring of the epidemic and help in planning in order to ensure strong enough efforts at sites (Asiimwe-Okiror et al., 1997; Moodie et al., 1991; Slutkin et al., 1988; Slutkin et al., 1990; Stoneburner \& Carballo, 1997, 2002; UNAIDS, 1998). These surveillance studies were supplemented by other studies. The effects of such an extensive and strong surveillance system itself is unknown, but its use by the program as a monitoring tool to strengthen and help target implementation was highly emphasized within the Uganda program. Changes in HIV seroprevalence occurred during the period between 1989 and 1992, with continued reductions in 1995 and 1997. An analysis past this period is beyond the scope of this article. The changes in sexual behavior and in HIV occurred during and within two to three years of Uganda's planned and extensively implemented AIDS education effort.

U.S. Census and UNAIDS estimates are of a $67 \%$ drop in Ugandan national prevalence between 1991 and 2001 (Singh et al., 2003; US House of Representatives, Hearing on the Global AIDS crisis and pandemic in Africa; 2000). For six sentinel surveillance sites measuring changes among 1524 year old antenatal women, reductions occurred from HIV prevalence rates of $15.0 \%-30.8 \%$ in 1989 to $7.4 \%$ to $14.7 \%$ in 1995 (see Table 4). 
Table 4 HIV prevalence (\%) changes in Uganda for 15-24 years old 1990-1993 and 1995-1996

\begin{tabular}{llll}
\hline $\begin{array}{l}\text { Antenatal sentinel } \\
\text { surveillance sites }\end{array}$ & $1990-1993$ & $1995-1996$ & $P$ \\
\hline Nsambya & $30.6(25-36)$ & $14.7(13-17)$ & $<.001$ \\
Rubaga & $24.0(18-30)$ & $17.5(14-21)$ & $<.05$ \\
Mbarara & $30.7(25-36)$ & $14.0(11-17)$ & $<.001$ \\
Jinja & $17.7(14-22)$ & $12.1(9-15)$ & $<.05$ \\
Mbale & $15.0(12-18)$ & $7.4(5-10)$ & $<.001$ \\
Tororo & $15.5(11-20)$ & $12.2(9-15)$ & $\mathrm{NS}$ \\
\hline
\end{tabular}

Summary and conclusions

Uganda developed the first, and what was soon to become, the strongest planned and best supported National AIDS program, with the largest national and international staffing and most intensive, broadly inclusive, decentralized and community based public education program in Africa. When Uganda was receiving \$18 million in support, other countries in the region were receiving between $\$ 1$ million to $\$ 4$ million. External and national financial support to the Uganda program was 4 to 20 times the amount provided to any other national program outside of the industrialized world at the time (Mann \& Tarantola, 1991; UNAIDS, 1998).

The messaging emphasized faithfulness and fidelity, although the IEC program at both national and district level provided information on all forms of HIV transmission and all forms of protection. Information on delaying age of onset of sexual activity and the protective value of condoms were included in the program. Counseling and testing and condom promotion were very small elements in the early years in which the changes in seroprevalence were first seen (Moodie et al., 1991; Uganda, 1989, 1993). Although condom knowledge was high, and use increased substantially, overall condom distribution was of the order of 4-6 million condoms/year; an amount of condoms that could not have influenced overall reductions in HIV prevalence as substantial as observed (Moodie et al., 1991; USAID, 2003). The $\mathrm{ABC}$ phrase was not known during these years, and it is estimated that it began to be used in the mid 90s - after the changes in Uganda had already taken place (USAID, 2003; Hardee, 2004). This does not take away from the fact that the full range of information was provided. Openness about AIDS, destigmatization, and promotion of care and compassion were also important components of the Ugandan program.

Abstinence itself was not specifically promoted on any posters, billboards, or leaflets of the national program as far as we remember, or as noted in any of the reports of the time. Delaying onset among young persons was promoted. It was already known to $\mathrm{WHO}$ at the time that providing full information about all means of transmission and ways of protection had been demonstrated to be the most effective approach to sexual behavior change, in particular for nonAIDS programs such as STD control, family planning and other programs, and therefore comprehensive education was the standard guidance of WHO/GPA health education guiding materials at the time (Grunsheit, 1994; UNAIDS, 1998).

Probably most importantly, the intensity of messaging of the Uganda program was far above any other program at the time. We recall returning from usual "mission travel" to multiple countries in the region including Rwanda, Burundi, Kenya, Tanzania, and sometimes Malawi or Zambia, and noting that there was no comparison between what was going on in Uganda and the other countries. This usually referred to the amount of visibility of the program by way of billboards and other public education materials, and the amount of decentralized program activity. Nevertheless it was not our impression at that time that this would necessarily translate into effective change. The thinking at the time was that there needed to be a still more professionally designed IEC program with more of a strategic basis, findings and criticisms that were noted in the 1988 program review and common among many of the review participants at the time, and a problem thought common to all programs in the region. It was a few years later that Hornik (2002) would reveal the close relationship between intensity of messaging and behavior change, and the large importance of intensity for several other public health/behavior change issues as well.

President Musevini's commitment and personal leadership and the involvement of the whole government was well known to all staff at WHO at the time and throughout the continent. This allowed open discussion throughout the country and even more so encouraged it. The President guided all ministers and other senior level government officials to mention and speak about AIDS at all public functions. As a matter of policy President Musevini's speeches were to end with a note on HIV/AIDS. As far as we know, no single speech, local or international, ended without talking about HIV/AIDS. A note was always left to himself to use his knowledge and imagination to convey the message.

There is nothing intrinsically different about the Ugandan people, problem or program, although the Resistance Council structure did facilitate some aspects of the decentralization performed, and the post-revolutionary nature of the society at the time probably helped ensure an appropriate amount of zeal for the effort. However the implementation of the program itself was notably different as compared to all of the neighboring countries at the time. We believe that the principal difference between the Uganda's HIV/AIDS prevention and education campaign and that of neighboring countries relates mostly to the intensity, depth, breadth, and extensiveness of programming of its behavior change campaign, the level of involvement of all sectors, the pragmatism and extension of the district level work deep into 
communities, including the involvement of local churches and mosques, and the high level of financial support that allowed this to occur. Although there are several matters different about the HIV/AIDS situation now, most notably the increased availability of drug treatment, it is still believed that given the full support, proper planning, and strength of implementation, serious HIV/AIDS prevention and public education campaigns of this nature, still largely missing in Africa, could and should be implemented in almost any country with this degree of problem or risk of problem.

For the most part in the late 1980s and early 1990s, the other countries in Africa were thought to be simply "behind" Uganda in planning, implementation and in their own movement toward enhanced support. The Uganda program was the first program, and for this reason as well as reasons of high donor concern, obtained very strong financial and other support. Uganda also had the commitment, and the ability to mobilize and decentralize the program, and to develop the management capacity to implement the IEC program at this broad and high level of effort.

Beginning in the early and mid 1990s serious interruptions in programming in neighboring countries began to occur as the WHO/GPA global effort began to be less globally coordinated, more bilaterally fragmented, and less prevention focused for various reasons partially explained elsewhere, but which include the change in leadership at WHO, the international preference for bilateral support, and a move toward UN/WHO coordination and consolidation without sufficient attention at the time to ensuring preservation of all relevant functions and priority to prevention (Slutkin, 2000). Some barriers to implementation and support may still exist in some countries, but there is no technical or program reason that the authors see today as to why all, or most other countries could not perform similar reversals today with appropriate planning, implementation, and intensity of effort and support to reverse their HIV/AIDS epidemics. With 5 million people being newly infected each year and treatment lagging further and further behind, programs with this leadership, programming, and intensity of effort need to be common rather than rare.

\section{Authors Biography}

Dr. Slutkin was the WHO/SPA and then WHO/GPA epidemiologist assigned to support the Uganda program from 1987-94. He also co-developed (along with Drs. Chin and Tarantola) the serosurveillance methods used to monitor trends in HIV within and among all countries (global), and supported the 12 other countries of Central and East Africa during the same years. Dr. Sam Okware was the director of the National AIDS Programme of Uganda. Dr. Warren Naamara was the epidemiologist responsible for the serosurveillance system of Uganda, and director of the Uganda
ACP from 1990-1993. Dr. Don Sutherland was the WHO Team Leader and epidemiologist assigned to Uganda following the work of Dr. Ros Widi-Wirski, now deceased whose trip reports were consulted. Donna Flanagan was the health educator assigned to Uganda from 1990-1994. Dr. Erik Blas provided the logistic, managerial and financial back-up support to the Uganda program, as well as dozens of other programs around the world from WHO/GPA. Dr. Paul Delay was the epidemiologist of the Malawi AIDS program and then the global USAID program director for AIDS, and subsequently Chief of Monitoring and Evalution for UNAIDS. Dr. Michel Carael worked in the social and behavioral research unit of WHO/GPA. Dr. Daniel Tarantola the Chief, National Programme Support was responsible for all national programs globally for WHO/GPA. During this time frame Dr. Tarantola supervised the development of over 120 national programs. The authors would also like to acknowledge Adjoa Amana, the driving force for the IEC training and messaging in the period 1987-90.

Acknowledgements This paper is dedicated to Dr. Jonathan Mann the founder and first director of the World Health Organization's Global Program on AIDS, who died in September 1998 in a plane crash; to Ros Widy-Wirski, the first WHO epidemiologist assigned to Uganda, who died in 1995 on a plane on his way back from his beloved Africa; to the popular Ugandan singer Philly Bongoley Lutaaya and to the dedicated Ugandan health educator Louis Ochero who both died of AIDS and all very dear friends.

\section{References}

Amana, A. (1990). End of Assignment Report to WHO/GPA; Uganda IEC Programme activities; MOH; AIDS Control Programme $\mathrm{MOH}$, Uganda.

Asiimwe-Okiror, G., Opio, A. A., Musinguzi, J., Madraa, E., Tembo, G., \& Carael, M. (1997). Change in sexual behavior and decline in HIV infection among young pregnant women in urban Uganda. AIDS, 11, 1757-1763.

Atkinson, B. (1989). Uganda; Contraceptive Supply Status Review; FPLM Project, August 25-September 18, 1989.

Gregson, S., Garnett, G., Nyamukapa, C. A., \& Hallet, T. B. (2006). HIV decline Associated with Behavior Change in Eastern Zimbabwe. Science, 311, 664-666.

Grunsheit, A. C., Kippax, S., Aggleton, P. A., Baldo, M., \& Slutkin, G. (1997). Sexuality, education, and young people's sexual behavior: A review of studies. Journal of Adolescent Research, 12, 421-453.

Hornik, R. C. (2002). Public Health Communication; Evidence for Behavior Change. Lawrence Erlbaum Associates, Publishers.

Mann, J. M., \& Tarantola, D. T. (1991). AIDS in the World. Cambridge, MA: Harvard University Press.

Mason, C. J., Markovitz, L. E., \& Kitsiripornchai, S. (1995). Declining prevalence of HIV-1 infection in young Thai men. AIDS, 9, 10611065.

Moodie, R., Katahoire, A., Kaharuza, F., Balika, D. O., Buusulwa, J., \& Barton, T. (Jan 1991). An evaluation study of Uganda AIDS control programme's information, education, and communication activities; $A C P / M O H$ Uganda and WHO/GPA.

Parkhurst, J. O. (2002). The Ugandan success stury? Evidence and claims of HIV-1 prevention. Lancet, 360, 78-80. 
SIDA/AIDS WHO. (1992). Report of the External Review of the World Health Organization's Global Programme on AIDS, Jan 1992. WHO/GPA/GMC (8)/92.4. Geneva: World Health Organization.

Singh, S., Darroch, J. E., \& Bankole, A. (2003). ABC in Uganda: The role of Abstinence, Monogamy and Condom Use in HIV Decline; The Allan Guttmacher Institute; Occasional Report No. 9.

Slutkin, G., Chin, J., Tarantola, D., \& Mann, J. (1988). Sentinel surveillance for HIV: a method to monitor HIV infection trends in population groups. WHO/GPA/DIR/88.8. Geneva: World Health Organization.

Slutkin, G., Chin, J., Tarantola, D., Mann, J. (1990).Use of HIV surveillance data in national AIDS programmes. WHO/GPA/SFI/90.1. Geneva: World Health Organization.

Slutkin, G. (2000). Global AIDS 1981-1999: the response. International Journal of Tuberculosis and Lung Disease, 4, S24-S33.

Stoneburner, R. L., \& Carballo, A. (1997). An assessment of Emerging Patterns of HIV Incidence in Uganda and Other East African Countries; Final Report of Consultation; Family Health International AIDS Control and Prevention Programme; International Centre for Migration and Health; 29.

Stoneburner, R., Low-beer, D., Barnett, T., Whiteside, A. (2002). Enhancing HIV Prevention in Africa: Investigating the Role of Social Cohesion on Knowledge Diffusion and Behavior Change in Uganda; presentation to USAID. Washington DC.
Stoneburner, R., \& Low-Beer, D. (2004). Population-level HIV declines and behavioral risk avoidance in Uganda. Science, 304, 1477.

Tarantola, D. (1996). Grande et petite histoires des programmes SIDA. Le Journal du SIDA, 86-87, 109-116.

Uganda AIDS Control Programme. (1989). Uganda AIDS Control Programme 1989-1990. Entebbe, Uganda: Ministry of Health.

Uganda (1993). Uganda National Operational Plan for HIV/AIDS/STD Prevention, Care, and Support 1994-1998.

Uganda (1995). Country Health Profile; CIHI Country Health Profile Series. Center for International Health Information.

UNAIDS (1998). Reaching regional consensus on improved behavioral and serosurveillance for HIV: report from a regional conference in East Africa; Joint United Nations Program on HIVIAIDS. Geneva.

UNAIDS case study (1998). A measure of success in Uganda: The value of monitoring both HIV prevalence and sexual behavior.

USAID (1998). Condom estimations, USAID, 1993-1998. USAID; Washington, DC: USAID.

USAID (2003). Sexual Behavior, HIV and Fertility Trends: A comparative analysis of Six Countries; Phase I of the ABC Study.

U.S. House of Representatives, Hearing on the Global AIDS crisis and pandemic in Africa; March 2000. Testimony of J. Sherry, G. Slutkin, R. Dellums, R. Holcroft

WHO Global Programme on AIDS 1987-1995: Final Report with emphasis on 1994-95 biennium. WHO/ASD/97.1, Geneva: World Health Organization, 1997.5 